\title{
Cooperative work and continuous assessment in an Electronic Systems laboratory course in a Telecommunication Engineering degree
}

\author{
Josep Jordana, Francesc J. Sànchez \\ Department of Electronic Engineering \\ Castelldefels School of Technology (EPSC) \\ Castelldefels. Spain \\ jordana@eel.upc.edu, francesc.josep.sanchez@upc.edu
}

\begin{abstract}
Electronic laboratory courses offer the possibility to introduce some specific and transversal skills to the curriculum of the students who follow an engineering degree. This paper examines the methodology and assessment which are applied in the laboratory course of the subject "Electronic Systems" in the second year course in the Telecommunication Engineering degree from the Castelldefels School of Technologyy (Escola Politècnica Superior de Castelldefels, EPSC) at the Universitat Politècnica de Catalunya (UPC). During 14 laboratory weekly sessions of $2 \mathrm{~h}$, students must analyze and design the analog and digital circuitry for an ultrasound-based distance measurement system, by means of several guided practices. Small groups of two or three students worked on a collaborative way, while the teacher acted as a guide to facilitate project comprehension and knowledge acquisition. The experience we describe corresponds to the Spring term of 2009, a period in which this methodology was applied to two small class groups of about 23 and 7 students respectively. This work studies the influence of the initial characteristics of the students and their time devoted to prepare the subject, on their academic performance. The paper finishes with a list of recommendations in order to improve students learning process and course assessment.
\end{abstract}

Keywords- Collaborative work, electronics engineering education, circuit analysis, circuit simulation

\section{INTRODUCTION}

It is well known that main general skills that enterprises demand for graduates of engineering programs are: teamwork, creative thinking and communication. To accomplish these requirements class activities must be learner-centred and teachers must become guides in the learning process [1]. The variety of skills that engineering students should master is increasing. There are several pedagogical methods that have been adopted in response to these needs [2]. There is much research showing that students who work cooperatively obtain better results and benefits from their relationships far more than students who do so competitively and individually. Cooperative learning [3] is the instructional use of small groups for students to work together to maximize their learning and that of their peers. Among the advantages of working cooperatively in small groups we can mention that it reinforces learning and improves skills and social relationships. It is a way of making students active cognitively. There are different studies related to the laboratory classes in courses on electronic technology where active learning is promoted [4], [5], [6].

It is very difficult to be objective when assessing laboratory work. In order to tend to give an objective global mark to the students it is very useful to consider applying a varied set of evaluation activities.[7]. Therefore we should use a variety of assignments to measure achievement of student learning [3]. The evaluation of the subject would be continous and it should promote the learning process. The feedback during this process promote competence development.

The present work is focused on: methodology (cooperative work and portfolio) and continuous assessment applied in the laboratory classes of Electronic Systems in the second year course (year 2000 Curriculum) in the Telecommunication Engineering degree from the Castelldefels School of Technology. We try to assess not only the specific course content, but also cross-curricular skills like: effective writing, critical thinking, collaborative work, and information organization. Indeed, these are the basic ideas that we try to convey through the introduction of the student learning portfolio [8]. The correct acquisition of a given competence is demonstrated by doing. For this reason skill assessment must be done through the activities and laboratory assigments students carry out.

\section{COURSE ORGANIZATION AND OBJECTIVES}

The course Electronic Systems is taught during the first semester of the second year. It consists of 6 credits, 3 credits corresponding to theoretical concepts and 3 credits corresponding to laboratory practices. The dedication of the student's work to the course is about 112 hours, which spread over 14 sessions of $8 \mathrm{~h}$ per week, equivalent to about 4,8 ECTS. The course has both a theoretical and a practical component, being laboratory class attendance obligatory. Students perform 2 hours of weekly lectures (classes have a maximum capacity for 45 students) and 2 weekly laboratory practices (laboratories have a maximum capacity for 20 students). This study corresponds to the Spring semester 2009 which has taken into account 30 students, divided in two laboratory-groups of 23 students (Group A) and 7 students (Group B) respectively. This number of students,

This work has been sponsored by the UPC-SLT project: "Consolidation and enhancement of the web of resources of Digital Systems, to support content and language integrated teaching (CLIL) at the EPSC" 
corresponding to each group, only depends on the registration procedure carried out during the beginning of the term. Because of the small number of the participants involved in the study it is difficult to generalize the results, but like in other studies with few students useful qualitative conclusions can be obtained [9] [10].

After completing the course, students will be able to:

- $\quad$ Explain the design flow of electronic systems based on microcontrollers: sensors and actuators, conditioning circuits, power supply calculations, SPICE-based simulations, error analysis, assembly language programming, etc.

- Assemble circuits of medium complexity to check their basic knowledge of circuit theory and skills in laboratory instrumentation and prototyping tools.

- Work cooperatively with other students in order to design and assemble an electronic system (an application project integrating a large part of the course content).

- Write technical reports characterizing the behaviour of the electronic system.

- Compare experimental results with simulations and theoretical concepts.

In order to facilitate the student's acquisition of all these specific and cross curricular skills, cooperative work and continuous and formative assessment of student assigments is applied.

\section{A. Cooperative Work}

In laboratory classes students are required to work cooperatively in order to increase the communication between group members and reinforce their interdependence. The first day of the class the teacher explains the objectives of the laboratory and the rules that must be followed. These practices are conducted in groups of 2 or 3 people. Although it would be preferable that these groups were heterogeneous [11] they were formed according to their preferences of friendship in order to avoid problems of making meetings outside the laboratory. Each practice group should have a notebook and a portfolio. The laboratory notebook consists of a spiral pad size sheet on which students record all the sequential information (connection diagrams of the assembly, numerical calculations, instructor explanations, etc.) gathered during the laboratory practice. Taking notes in this notebook tries to inculcate the habit of scientific work to the students. The aim of this approach is that they can faithfully reproduce all the practices of the course.

The portfolio contains both students' works and reflections about the way they have learnt in cooperation during the laboratory term. The evaluation criteria are held continuously over the laboratory assigments, thus, the portfolio shows the way the student abilities have changed or improved over time.

Each cooperative group has to understand that individual success will be achieved from group's success; students have to believe that they "sink or swim together" [3], so that each member must ensure that their partner has assimilated the concepts and skills for each practice. During laboratory sessions instructors ask questions to any of the students in the group randomly and the marks are assigned to the whole group. This assessment ensures that students take seriously this learning process and verify that anyone in the group knows how to answer teacher's questions.

Laboratory practices are intended to design the analog and digital circuitry for an ultrasound-based distance measurement system. At the beginning of each session, students, in groups, must show the preliminary study to the teacher, which involves answering a series of theoretical issues relating to the practice implemented in the current session. To ensure a maximum profit from practical laboratory classes it is essential that students undertake this assignment. The teacher highlights in situ the errors that students may have done; they are able to correct them immediately; and as a consequence, the group's final report is improved by this fast feedback.

At the same time, to the development of each laboratory practice, students should complete a simplified report per session of two pages during the last 10 minutes of the session. This report consists of a summary of the major activities performed in each session and contains several basic questions related to the preliminary study and the experimental activities. In addition, the students can add their reflections [9] and questions being raised during the development of laboratory classes. At the beginning of the next session, the teacher delivers the report corrected, which ensures that students analyse the successes and mistakes they have committed.

\section{B. Evaluation Of The Laboratory Classes}

The evaluation currently being applied in the EPSC and in many other Schools of the UPC is the formative assessment which consists in carrying out a continuous assessment throughout the course [12]. The teacher-student feedback, introduced by the formative assessment, permits to correct the imbalances that may occur during the course, adapting teaching classes to each situation. For this reason, students and teachers have regular information during the course about the teachinglearning process.

Activities in the laboratory have assigned a weight of $45 \%$ of the global grade. In order to assure formative assessment, the final laboratory grade is based on the following items:

- Two reports $(10 \%)$. Written reports were collected in the middle of the term and at the end, corresponding to the analog and digital designs respectively.

- Laboratory work, preliminary studies, reports of each session and portfolio $(25 \%)$. It takes into account the functioning of the practice and the answers to questions from the teacher.

- $\quad$ An individual laboratory exam (10\%). This test takes place at midterm, and it is a reference to the teacher to find out if indeed the cooperative learning has been successful, because if so, the members of each group should obtain similar scores. 


\section{ACADEMIC PERFormance ACHIEVEd By StUdents AND STUDENT TIME DEVOTED TO THE SUBJECT}

The academic performance achieved by students is related with the pedagogical methodology applied, but it is also influenced by the past of the students. For this reason, in order to know what type of students attended the laboratory, at the first class of the course the students filled in a survey which consisted of several questions related to: address, previous studies, admission mark to the university, coursed subjects related to electronics, etc.

Analysing the survey of the two laboratory groups we find that most students come from Barcelona or its surroundings. Most of them, $71 \%$, began their studies in the fall semester 2007 , respect the $29 \%$ that began their university studies in the fall semester 2006. Because this subject corresponds to the first semester of the second year, these percentages indicate that most of the students have failed some subjects of their degree for whatever reason and perhaps are not the most brilliant or not the most motivated to study to the expected level.

As we can see in Table I, most of the students come from baccalaureate: $73,3 \%$ respect to $26,7 \%$ who come from professional modules. The percentages are similar in both class groups. In group A the number of students who attend the subject for the first time $(47,8 \%)$ is slightly lower than the number of repeating students $(52,2 \%)$. However, in group B most of the students $(71,4 \%)$ attend the subject for the first time.

TABLE I. DISTRIBUTION OF THE STUDENTS IN FUNCTION OF THEIR PREVIOUS STUDIES AND IN FUNCTION OF REPEATERS AND NON REPEATERS.

\begin{tabular}{|c|c|c|c|c|}
\multicolumn{1}{c}{ Number of } & \multicolumn{1}{c}{ Non } & \multicolumn{1}{c}{ Repeating } & \multicolumn{1}{c|}{ Baccalaureate } & Professional \\
\hline students & $\begin{array}{c}\text { repeating } \\
\text { students }\end{array}$ & students & & Modules \\
Group A (23) & $11(47,8 \%)$ & $12(52,2 \%)$ & $17(73,9 \%)$ & $6(26,1 \%)$ \\
\hline Group B (7) & $5(71,4 \%)$ & $2(28,6 \%)$ & $5(71,4 \%)$ & $2(28,6 \%)$ \\
\hline Total (30) & $16(53,3 \%)$ & $14(46,7 \%)$ & $22(73,3 \%)$ & $8(26,7 \%)$ \\
\hline & & & & \\
\hline
\end{tabular}

In Table 11 it is interesting to note that the percentage of students that have passed the subject is slightly higher for those that have coursed baccalaureate $(68,2 \%)$ than for those that have coursed professional modules $(62,5 \%)$. The highest percentage of pass rate is attributed to those students who repeat the subject $(71,4 \%)$.

On the other hand, if we center our study on the laboratory exam (done in the $8^{\text {th }}$ week), we can see that these percentages decrease significantly $(43,3 \%)$, except in group B where remain the same (Table III). Although both groups have few students, this result confirms that generally, smaller class groups have a higher pass rate than more numerous groups. This can be attributed to the fact that in group B a higher percentage of students attends the subject for the first time. Furthermore, subjective observations made by the teacher showed, in percentage, a higher motivation of laboratory work for students of the group B.
TABle II. Distribution Of The Students That Have Passed The SUBJECT.

\begin{tabular}{|c|c|c|c|c|}
\hline Students that & Non & Repeating & Baccalaureate & Professional \\
\hline $\begin{array}{l}\text { have passed } \\
\text { the subject }\end{array}$ & $\begin{array}{c}\text { repeating } \\
\text { students }\end{array}$ & students & & Modules \\
\hline Group A (14) & $5(45,4 \%)$ & $9(75 \%)$ & $11(64,7 \%)$ & $3(50 \%)$ \\
\hline$(60,1 \%)$ & & & & \\
\hline Group B (6) & $5(100 \%)$ & $1(50 \%)$ & $4(80 \%)$ & $2(100 \%)$ \\
\hline$(85,7 \%)$ & & & & \\
\hline Total (20) & $10(62,5 \%)$ & $10(71,4 \%)$ & $15(68,2 \%)$ & $5(62,5 \%)$ \\
\hline$(66,7 \%)$ & & & & \\
\hline
\end{tabular}

Like in the global pass rate, we observe that baccalaureate students have a slightly higher pass rate than professional modules students, but in this case repeaters and non repeaters obtain very similar results. A possible interpretation could be that the practical exam only consisted on theoretical questions respect to the practices. If it had included some practical exercises using the instrumentation and assembling circuits it is possible that students who came from professional modules would have obtained better results. Time devoted to solve the exam is another aspect to take into account, because more time you lend to students better results they would obtain.

TABLE III. Distribution Of The Students That Have Passed The LABORATORY EXAM.

\begin{tabular}{|c|c|c|c|c|}
\hline Students & Non & Repeating & Baccalaureate & Professional \\
\hline $\begin{array}{l}\text { that have } \\
\text { passed the } \\
\text { lab-exam }\end{array}$ & $\begin{array}{c}\text { repeating } \\
\text { students }\end{array}$ & students & & Modules \\
\hline Group A (7) & $2(18,2 \%)$ & $5(41,7 \%)$ & $6(35,3 \%)$ & $1(16,7 \%)$ \\
\hline$(30,4 \%)$ & & & & \\
\hline Group B (6) & $5(100 \%)$ & $1(50 \%)$ & $4(80 \%)$ & $2(100 \%)$ \\
\hline$(85,7 \%)$ & & & & \\
\hline Total (13) & $7(43,8 \%)$ & $6(42,9 \%)$ & $10(45,5 \%)$ & $3(37,5 \%)$ \\
\hline$(43,3 \%)$ & & & & \\
\hline
\end{tabular}

Another parameter of interest in our study is the distribution of students according to their admission mark to the university (Table IV). After processing the data, we see that most of the students are concentrated in the range of marks between 5 and 7 . A number of 25 responses were processed because 5 students didn't inform about their admission mark in the first questionnaire.

TABLE IV. DISTRIBUTION OF THE STUDENTS ACCORDING TO THEIR ADMISSION MARK TO THE UNIVERSITY.

\begin{tabular}{|c|c|c|c|c|}
\hline Number of & {$[5,6)$} & {$[6,7)$} & {$[7,8)$} & {$[8,9)$} \\
\hline students & & & & \\
\hline Group A (20) & $4(20 \%$ & $11(55 \%)$ & $4(20 \%)$ & $1(5 \%)$ \\
\hline Group B (5) & $1(20 \%)$ & $3(60 \%)$ & $1(20 \%)$ & - \\
\hline Total(25) & $5(20 \%)$ & $14(56 \%)$ & $5(20 \%)$ & $1(4 \%)$ \\
\hline
\end{tabular}

Tables $V$ and $\nabla 1$ show an interesting result: there 1s no direct relationship between the admission mark and the subject pass-rate. In this sense, we can observe that the pass-rate is higher for those students who entered with the lower admission mark. This result contrasts with the one found in [12], where this correlation was shown to be higher, because the analyzed subject corresponded to the first term of the first year course of the degree. 
TABLE V.

DisTRIBUTION OF THE STUDENTS WHO HAVE PASSED THE SUBJECT ACCORDING TO THEIR ADMISSION MARK TO THE UNIVERSITY.

\begin{tabular}{|c|c|c|c|c|}
\hline $\begin{array}{l}\text { Students who } \\
\text { have passed } \\
\text { the subject }\end{array}$ & {$[\mathbf{5 , 6 )}$} & {$[\mathbf{6 , 7})$} & {$[\mathbf{7 , 8 )}$} & {$[\mathbf{8 , 9})$} \\
\hline Group A (14) & $4(100 \%)$ & $7(63,6 \%)$ & $3(75 \%)$ & $0(0 \%)$ \\
\hline Group B (4) & $1(100 \%)$ & $2(66,7 \%)$ & $1(100 \%)$ & - \\
\hline Total (18) & $5(100 \%)$ & $9(64,3 \%)$ & $4(80 \%)$ & $0(0 \%)$ \\
\hline
\end{tabular}

TABLE VI. DISTRIBUTION OF THE STUDENTS WHO HAVE PASSED THE LABORATORY EXAM ACCORDING TO THEIR ADMISSION MARK TO THE UNIVERSITY.

\begin{tabular}{|c|c|c|c|c|}
\hline $\begin{array}{l}\text { Students who have } \\
\text { passed the lab- } \\
\text { exam }\end{array}$ & {$[\mathbf{5 , 6 )}$} & {$[\mathbf{6 , 7 )}$} & {$[\mathbf{7 , 8 )}$} & {$[\mathbf{8 , 9 )}$} \\
\hline Group A (7) & $3(75 \%)$ & $3(27,3 \%)$ & $1(25 \%)$ & $0(0 \%)$ \\
\hline Group B (4) & $1(100 \%)$ & $2(66,7 \%)$ & $1(100 \%)$ & - \\
\hline Total (11) & $4(80 \%)$ & $5(35,71 \%)$ & $2(40 \%)$ & $0(0 \%)$ \\
\hline
\end{tabular}

Table VII shows the average marks of all items of the continuous assessment of the laboratory work. In addition we present the average marks corresponding to the two theory exams that are done in the midterm and at the end of the course. It can be seen that laboratory work and reports are the items with highest marks and the exams are the items with lowest marks. Students of group B have obtained higher marks than students of the group A on all evaluation items what agrees with instructor observations during the laboratory work. A consequence of this is that students rely on laboratory classes to pass the course, which diminish the pass-rate in exams.

TABLE VII. AVERAGE MARKS OBTAINED IN EACH ITEM OF THE CONTINOUS ASSESSMENT.

\begin{tabular}{|l|l|l|}
\hline Average marks & Group A & Group B \\
\hline Final mark & 4,4 & 5,3 \\
\hline Reports & 6,3 & 7,5 \\
\hline Laboratory-work & 6,4 & 7,4 \\
\hline Laboratory-exam & 2,3 & 5,9 \\
\hline Theory-exams & 2,9 & 3,8 \\
\hline
\end{tabular}

A possible cause to the low final average mark achieved by the students could be that they didn't spend enough time doing the activities and studying the different topics of the course. For this reason students were asked to evaluate during 8 weeks of the course (randomly selected) how much time they had spent studying for each session (both theory and laboratory classes). The results have been that in average, the students of the group A have employed 3,48 h/week and 3,61 h/week preparing theoretical and laboratory classes respectively. In group B students have spent 3,24 h/week and 4,33 h/week respectively. It should be noted that these times include the activities inside and outside of the class. They have spent more time preparing laboratory practices than studying theoretical ones, what is reflected in the lower marks of theoretical exams. These results are slightly lower to the instructors' previsions of $4 \mathrm{~h}$ per week in average.
Fig. 1 shows the relationship between the average of hours per week that each student of the group A devote to the whole subject and the final mark obtained. The time value that appears in the figure is the average of theoretical and laboratory work per week, that approaches 4 h. Fig. 2 corresponds to the time devoted by students of the group B. In both groups, we don't see a direct relation between the pass rate of the students and their time devoted to the subject. The correlation coefficients have a low value: $-0,2907$ and 0,3345 respectively.

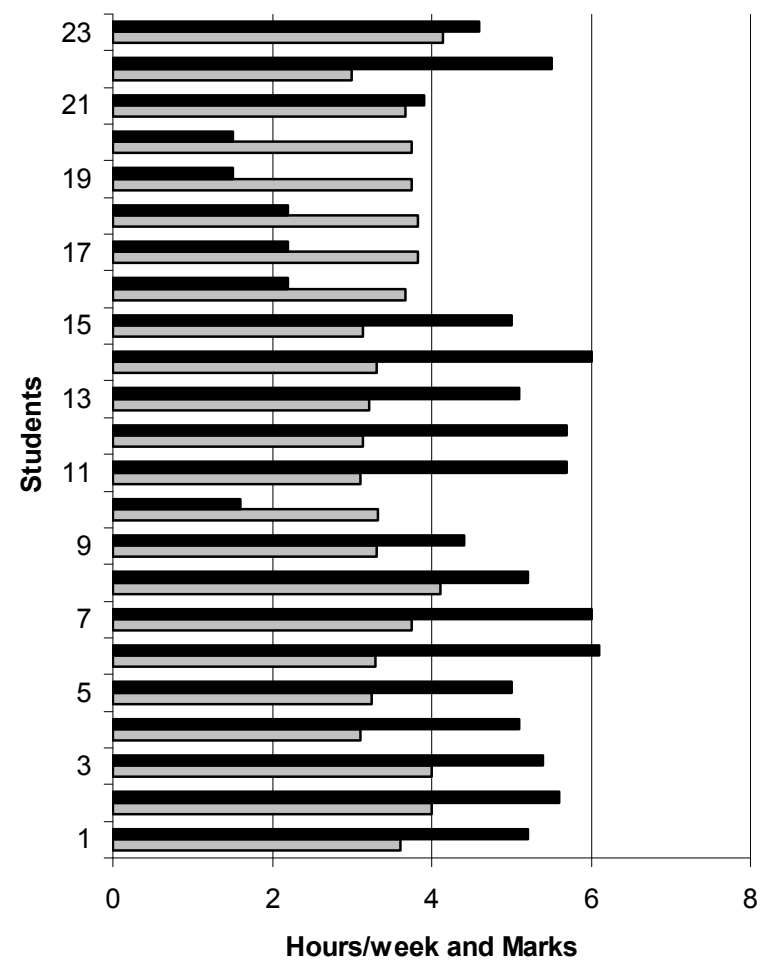

Figure 1. Average time devoted to study the subject (grey) and final mark (black) obtained by each student of Group A.

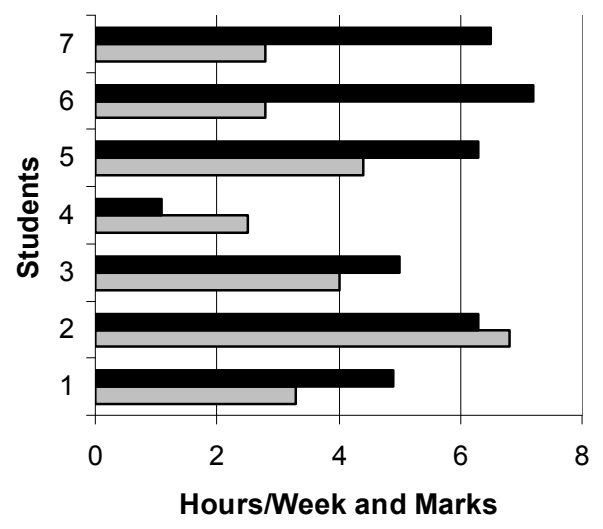

Figure 2. Average time devoted to study the subject (grey) and final mark (black) obtained by each student of Group B. 


\section{FINAL FEEDBACK AND FUTURE IMPROVEMENTS}

To collect the student's views about the teaching process and to get feedback from them, an adaptation of the Student Experience of Education Questionnaire (SEEQ) was carried out at the end of the course. Around 19 students took part in the survey. In Table VIII we have selected some of the most representative questions we have raised in the two class groups. Students were asked to punctuate each question in a scale from 1 to 5, as: 1. Strongly disagree, 2. Disagree, 3. Neutral, 4. Agree, 5. Strongly agree.

TABLE VIII. SEEQ QUESTIONNAIRE. MOST REPRESENTATIVE QUESTIONS, RELATED TO THE METHODOLOGY APPLIED IN THE COURSE.

\begin{tabular}{|c|c|c|}
\hline Questions & $\begin{array}{c}\text { Group A } \\
(16) \\
(70 \%)\end{array}$ & $\begin{array}{c}\text { Group } \\
\text { B } \\
(3) \\
(43 \%)\end{array}$ \\
\hline $\begin{array}{l}\text { I have also learned more English, to work } \\
\text { cooperatively and make oral presentations }\end{array}$ & 2,94 & 2,33 \\
\hline $\begin{array}{l}\text { The teacher has been dynamic and active } \\
\text { during classes of group work and has followed } \\
\text { our work }\end{array}$ & 3,88 & 3,67 \\
\hline $\begin{array}{l}\text { Classes have been clear and the } \\
\text { explanations have been a good material for } \\
\text { understanding the subject }\end{array}$ & 3,94 & 4,33 \\
\hline $\begin{array}{l}\text { Course material was well prepared and has } \\
\text { been carefully explained }\end{array}$ & 3,94 & 3,67 \\
\hline $\begin{array}{l}\text { Group work in classes timetable has been } \\
\text { useful and well organized }\end{array}$ & 3,87 & 4,33 \\
\hline $\begin{array}{l}\text { The classes of group work that we have } \\
\text { organized outside the regular timetable, have } \\
\text { been profitable and useful }\end{array}$ & 3,88 & 4,0 \\
\hline $\begin{array}{l}\text { Cooperative working groups have been a } \\
\text { good tool to study and learn the subject and } \\
\text { share knowledge and ideas }\end{array}$ & 4,06 & 3,0 \\
\hline $\begin{array}{l}\text { Instructot's comments on the corrected work } \\
\text { and exams were very helpful }\end{array}$ & 3,69 & 3,33 \\
\hline $\begin{array}{l}\text { The methods of evaluation of this course are } \\
\text { fair and appropriate }\end{array}$ & 3,81 & 3,33 \\
\hline $\begin{array}{l}\text { The contents of examinations and other } \\
\text { evaluated assignments, correspond to the course } \\
\text { contents, in accordance with the emphasis } \\
\text { placed on each subject by the teacher }\end{array}$ & 3,69 & 4,0 \\
\hline $\begin{array}{l}\text { The portfolio helped me to organize my } \\
\text { study during the course }\end{array}$ & 3,44 & 4,0 \\
\hline $\begin{array}{l}\text { The workload of this course compared with } \\
\text { others, has been: very small (1), Small (2) } \\
\text { Normal (3) Great (4) Very large (5) }\end{array}$ & 3,56 & 3,5 \\
\hline $\begin{array}{l}\text { I would recommend cooperative learning in } \\
\text { other subjects of the grade }\end{array}$ & 3,50 & 3,0 \\
\hline
\end{tabular}

It can be seen that all items are well punctuated, with average marks of 3,71 in the group $\mathrm{A}$ and 3,58 in group $\mathrm{B}$, what indicates that student valuation of this methodology is good.
From the analysis of the results relating to the academic performance and taking into account the feedback received by the students, some improvements that we propose for future laboratory courses are:

- In order to be more objective assessing each student individually it would be useful to give them some written questions, five minutes before the end of each laboratory class. These basic questions could be drawn up in English, because it is an important crosscurricular to be introduced.

- The laboratory exam should include not only theoretical questions but also practical experiments. It would be done at the end of the term instead of the midterm, in order to take into account not only the analog block of the electronic system but also the digital block.

- Although some groups did very well write portfolios, we consider that too little time was reserved to assess the portfolio, because some groups collected the information few days before was presented to the instructor. Students would consider more important its realization if it was graded highly in the assessment process.

- Although the good quality of some written reports collected at the end of the analog block and at the end of the digital block, we have observed some plagiarisms. They could be avoided giving a more detailed writing model to follow, which can be changed from one course to another.

- In order to improve theory exam grades it would be very interesting that laboratory assignments were more related with theory contents and vice versa.

- Students should complete a report about their collaborative work during group meetings done outside the laboratory, in order to reflect about this active learning methodology, when the instructor is not present.

\section{CONCLUSIONS}

This paper has analyzed the ongoing methodology and assessment which have been applied in the laboratory course of the subject "Electronic Systems" in the Telecommunication Engineering degree from the Castelldefels School of Technologyy (EPSC). The experience that we have described corresponds to the Spring term of 2009, a period in which the authors of this work have studied two laboratory groups of about 23 and 7 students respectively.

This work relates the academic performance with the initial characteristics of the students, obtained from the analysis of the responses to a questionnaire that was given to the students the first session of the course. The highest percentage of students who passed the subject occurred in students coming from the baccalaureate or who had repeated the course and no clear correlation between overall academic performance and admission mark to the university was observed. 
Students were asked to evaluate how much time they had spent studying for this course. Taking into account the information given by the students and the marks obtained, we conclude that they don't spend enough time preparing the subject. This study also shows that the relationship between the time devoted to prepare the subject (inside and outside the class) and the marks obtained by the students are not correlated. Although there is no direct relationship between time and marks, some students would improve results if they made a more effort.

If instead of applying the continuous assessment, we only took into account exam grades (theoretical and practical), the pass rate would have been lower. Increasing better grades in exams is a challenge for future courses.

Continuous assessment and collaborative work improve the performance of students less prepared, but hinder the emergence of endnotes brilliant, because it is very difficult to get very good grades in all evaluation criteria.

Although academic performance should be improved, most of the students have had a favourable impression of the methodology applied in laboratory classes.

\section{REFERENCES}

[1] E. Montero, Ma J. González, "Student engagement in a structured Problem-Based approach to learning: A first-year electronic engineering study module on heat transfer," IEEE Trans. Educ., vol. 52, no. 2, pp. 214-221, May 2009.

[2] C. Savanter-Ranne, O.P. Lundén, S. Kolari, "An alternative teaching method for electrical engineering courses," IEEE Trans. Educ., vol. 51, no. 4, pp. 423-431, November 2008.
[3] D. Johnson, R. Johnson, K. Smith, "Active learning. Cooperation in the college classroom," Third Edition. Interaction Book Company. Minnesota (EUA), 2006. http://www.co-operation.org.

[4] J.P. Oliver, F. Haim, "Lab at home: Hardware kits for a digital Design Lab,” IEEE Trans. Educ., vol. 52, no. 1, pp. 46-51, February 2009.

[5] C.T. Medrano, M. Ubé, I. Plaza, A. Blesa, "The tools of quality in electronic engineering education,”. Eur. J. Eng. Educ., vol. 27, no. 4, pp. 325-337, 2002.

[6] Finkelstein, N.D. et al., "When learning about the real world is better done virtually: A study of substituting computer simulations for laboratory equipment," Physical Review Special Topics-Physics Education Research 1. 010103, 8 pages, 2005.

[7] L. Villardón, "Evaluación del aprendizaje para promover el desarrollo de competencias," Educatio siglo XXI, pp. 57-76, 2006.(in Spanish).

[8] J. Armengol, J. Hernández, J. Mora, J. Rubio, F. J. Sànchez, M. Valero, "Experiencias sobre el uso del portafolio del estudiante en la UPC," Revista de docencia universitaria. Año III, June 2009, http//www.um.es/ead/Red_U/m3.

[9] C. Poyatos "The IGRA (Individual group, classroom reflective action) technique: A partnership to improve teaching and learning." Research and Development in Higher Education, 24, pp. 137-150, 2001.

[10] J.D. Lynch, "Teaching digital system timing: a comprehensive approach," IEEE Transactions on Education, vol. 51, no. 3, pp. 325-330, August 2008.

[11] R. L. Pimmel, "A practical approach for converting group assigments into team projects," IEEE Transactions on Education, vol. 46, no 2, pp. 273-282, May 2003.

[12] J. Jordana, "Evaluación continua aplicada a la asignatura Componentes y Circuitos en su adecuación al Espacio Europeo de educación Superior (EEES)," Formación Universitaria. vol. 2, no. 1, pp. 37-44, 2009. doi:10.1612/form.unic.4130fu.08.(In Spanish). 